\title{
Circulating Leptin Concentrations in Patients with Chronic Obstructive Pulmonary Disease: A Systematic Review and Meta-Analysis
}

\author{
Lin Zhou ${ }^{\mathrm{a}}$ Cheng Yuan ${ }^{\mathrm{a}}$ Jingying Zhang ${ }^{\mathrm{c}}$ Rongbin $\mathrm{Yu}^{\mathrm{b}}$ Mao Huang ${ }^{\mathrm{a}}$ \\ Ian M. Adcock ${ }^{d}$ Xin Yao ${ }^{a}$ \\ a Department of Respiratory Medicine, The First Affiliated Hospital of Nanjing Medical University, \\ ${ }^{b}$ Department of Epidemiology and Biostatistics, School of Public Health, Nanjing Medical University, and \\ 'Department of Respiratory Medicine, Jiangsu Province Hospital of Traditional Chinese Medicine, Nanjing, China; \\ ${ }^{\mathrm{d}}$ Airway Disease Section, National Heart and Lung Institute, Imperial College, London, UK
}

\section{Key Words}

Acute exacerbations · Circulation · Chronic obstructive pulmonary disease $\cdot$ Leptin $\cdot$ Weight loss

\begin{abstract}
Background: Weight loss is a clinically important risk factor indicating a poor prognosis in chronic obstructive pulmonary disease (COPD). Leptin is an important regulator of food intake and energy expenditure. Objectives: To conduct a meta-analysis to determine whether the level of leptin is related to the disease status of COPD. Methods: Studies published before December 2012 were identified by searching PubMed, Embase and the Cochrane Database. Observational studies comparing circulating leptin levels between COPD patients and healthy controls were included. Data were independently extracted by two investigators and analyzed using Stata 12.0 software. Results: Ten articles were included in the meta-analysis. Circulating leptin levels were correlated with the body mass index (BMI) as well as percent fat mass in stable COPD patients. The correlation coefficient tended to be weaker during exacerbation. A positive correlation between leptin and tumor necrosis factor (TNF)-a levels was found in COPD exacerbations, while it disappeared in patients with stable disease. Most studies indicated that circu-
\end{abstract}

lating leptin levels in stable COPD patients were not significantly different from those in healthy controls when adjusted for gender and BMI, whilst leptin levels tended to elevate in exacerbation groups. Conclusions: The normal regulatory mechanism of leptin is maintained in stable COPD patients despite weight loss. The additional correlation between leptin and TNF-a during exacerbations may support the closer association of leptin with changes in nutritional parameters and suggests its valuable role in the evaluation of systemic inflammatory responses in COPD patients during exacerbation, which merits further study.

(c) 2013 S. Karger AG, Basel

\section{Introduction}

Chronic obstructive pulmonary disease (COPD) is characterized by persistent airflow limitation that is usually progressive and associated with enhanced chronic inflammatory responses to noxious particles or gases in the airways and lung [1]. COPD is projected to rank fifth as a worldwide burden of disease by 2020 [2], with approxi-

\section{Zhou and C. Yuan contributed equally to this paper.}

\section{KARGER}

E-Mail karger@karger.com

www.karger.com/res
(C) 2013 S. Karger AG, Basel

0025-7931/13/0866-0512\$38.00/0
Dr. Xin Yao

Department of Respiratory Medicine

The First Affiliated Hospital of Nanjing Medical University

300 Guangzhou Road, Nanjing 210029 (China)

E-Mail yaoxin@njmu.edu.cn 
mately $4.8 \%$ of all deaths per annum [3]. Weight loss and fat-free mass depletion may be often observed in COPD patients, which contribute significantly to morbidity, disability and handicap in COPD patients $[4,5]$.

However, the mechanism underlying weight loss in COPD patients remains unclear. Nutritional aspects including reduced food intake [6], impaired amino acid metabolism [7] and increased energy metabolism [8] are considered important causes for tissue depletion in COPD patients.

Leptin, the product of the obese $(\mathrm{Ob})$ gene, was initially discovered as a regulator of food intake and energy expenditure $[9,10]$, and has recently provided new insights into the pathophysiology of weight loss in COPD patients. Leptin levels increase acutely in patients with infection or inflammation [11] as well as during weight loss [12]. As a systemic disease, COPD is characterized by chronic airway inflammation, which is usually exacerbated by infection [13]. In 1999, Schols et al. [14] first demonstrated that plasma leptin levels were increased in COPD patients compared with healthy individuals. In addition, Bruno et al. [15] found that leptin expression was increased in the bronchial submucosa of COPD patients, and this increase was associated with airway inflammation and airflow obstruction. Many recent studies have reported the relationship between leptin and local or systemic inflammation. Some studies [16-20] suggested that leptin may play an important role in the mechanism of weight loss in COPD patients and might be a potential biomarker to reflect the clinical status of COPD.

However, most of these studies were heterogeneous in terms of sample size, nutritional support therapy and other characteristics, all of which may contribute to inconsistencies in the literature. Additionally, there is a lack of qualitative analysis regarding the possible involvement of leptin in the pathophysiology of COPD. Therefore, we conducted a systematic review and meta-analysis to further explore the role of circulating leptin levels in COPD. The aim of our work is to study possible relationships between circulating leptin levels and (1) nutritional aspects in COPD patients, (2) systemic inflammatory biomarkers of COPD, and (3) disease status of COPD.

\section{Materials and Methods}

Studies were identified by searching the literature using PubMed (1966 to December 2012), Embase (1980 to December 2012) and the Cochrane Database (1972 to December 2012) using both key words and free text words: ('pulmonary disease, chronic obstructive' [MeSH Terms] or 'chronic obstructive pulmonary disease' or 'COPD' or 'COAD' or 'chronic obstructive airway disease' or 'chronic obstructive lung disease' or 'emphysema' or 'chronic bronchitis') and ('leptin' [MeSH Terms] or 'leptin'). Leptin in the blood was retrieved manually. There was no language restriction.

Inclusion criteria included: (1) observational studies; (2) COPD patients who were diagnosed according to the criteria of the American Thoracic Society or Global Initiative for Chronic Obstructive Lung Disease, and (3) healthy controls who had no medical illness or abnormalities in physical examination and laboratory data, and presented no symptoms of infection.

Exclusion criteria included: (1) patients with conditions known to affect serum leptin, such as collagen vascular disease, metabolic or endocrine diseases, renal or liver insufficiency and cardiac failure [21] or treatment with certain drugs [22]; (2) patients who received nutritional support therapy, and (3) patients with a history or diagnosis of asthma, allergy or other respiratory diseases other than COPD.

Two reviewers (L.Z. and C.Y.) extracted the data from studies independently by reviewing the titles and abstract sections. Full articles were searched when the information met the inclusion criteria. If there was any doubt or disagreement, the full article would be reviewed and opinions would be sought from a third party (X.Y.), or the authors would be contacted for further clarification. For each accepted study, the following data were extracted: the number of participants, age, gender, clinical features, treatments, methods of measuring leptin, mean value, SD, SEM and $95 \% \mathrm{CI}$ of both patients with COPD and healthy subjects, and the percentage predicted values of the forced expiratory volume in $1 \mathrm{~s}\left(\mathrm{FEV}_{1}\right)$. The SEM or $95 \%$ CI was transformed into SD using statistical formulas. Body mass index (BMI) was calculated according to the equation $\mathrm{BMI}=$ weight $(\mathrm{kg}) / \mathrm{height}^{2}\left(\mathrm{~m}^{2}\right)$. Fat mass $(\mathrm{FM})$ was measured with bioelectric impedance analysis. Fisher's $\mathrm{z}$ transformation of the correlation coefficient [23] between the circulating leptin and BMI or FM\% was used to transform $r$ to $\mathrm{z}$, which is considered as the normal distribution.

Stata Software version 12.0 was used for analytical study. Weighted mean difference was selected to combine statistics, while the standard mean difference was selected if the difference in mean values was too large or resulted in large heterogeneity. Summary estimates and the weightings for each outcome were evaluated based on DerSimonian-Laird random effect models. The MantelHaenszel method was chosen to test heterogeneity of the studies. Heterogeneity was tested and significance was set at $p<0.05$. A fixed effect model was used unless there was significant heterogeneity $\left(\mathrm{I}^{2}>50 \%\right)$, in case of which a random effect model would be used.

\section{Results}

The systematic search (fig. 1) yielded a total of 721 references, of which 491 were unique. After review of the titles, 369 studies were excluded, yielding 122 articles. A subsequent review of the abstracts rejected an additional 74 references, yielding 48 candidate studies. Of the 48 studies, 9 did not provide sufficient leptin data, such as 
Fig. 1. Results of the systematic literature search. Nine studies were not suitable for meta-analysis because either the control subjects and COPD patients in these studies were not matched for BMI and FM\% or the correlation coefficients were not provided.
PubMed $(n=71)$

Embase $(n=636)$

Cochrane $(n=14)$

Total $(n=721)$

Duplicate $(n=230)$

References rejected on title review

Not human $(n=19)$

Not COPD $(n=305)$

Not relevant $(n=45)$

Relevant studies

$(\mathrm{n}=122)$

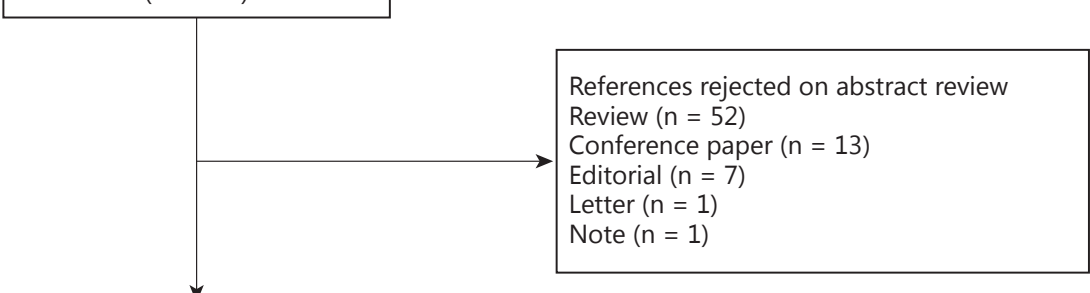

Potentially appropriate studies for inclusion $(n=48)$

Full text review

Use nutritional support $(n=4)$

No original data $(n=9)$

Not in blood $(\mathrm{n}=5)$

Comorbidities $(n=10)$

Medication (except corticosteroids)

which affects leptin levels $(n=1)$

19 references included

Data not suitable for meta-analysis $(n=9)$

10 references included mean value, SD, SEM and 95\% CI; 4 had no data of circulating leptin levels; 10 had comorbid diseases that could affect serum leptin; 4 received nutritional support therapy, and 1 used megestrol acetate [22] that might have influenced circulating leptin levels. We attempted to contact the corresponding and lead authors by e-mail to obtain further information. Finally, 19 articles involving a total of 721 subjects were included in our study and 10 of them were suitable for meta-analysis. Nine studies have been excluded because in these studies either the control subjects and COPD patients were not matched for BMI and/or FM\%, or the data needed, such as the correlation coefficient, were not provided.

\section{Relationship between Circulating Leptin Levels and} Nutritional Aspects of COPD Patients

Data were pooled from 10 studies irrespective of the age, sex, nutritional aspects of the participants, and the severity of disease or measurements (table 1 ). The $\mathrm{z}$ value was 0.81 (95\% CI, 0.49-1.14; $\mathrm{p}<0.001 ; \mathrm{I}^{2}=81.0 \%$; random effect model) in stable COPD patients and 0.48 (95\% CI, 0.21-0.75; $\mathrm{p}<0.001 ; \mathrm{I}^{2}=0.0 \%$; fixed effect model) during acute exacerbations of COPD (AECOPD).

There was a significant positive strong correlation between circulating leptin levels and BMI in healthy controls $(\mathrm{r}=0.748)$, while this relationship was weaker in both stable COPD patients $(r=0.67)$ and patients with AECOPD 
Table 1. Correlation between circulating leptin levels and nutritional parameters

\begin{tabular}{|c|c|c|c|}
\hline First author, year & Group & $\mathrm{n}$ & r value or main message \\
\hline Takabatake [29], 1999 & $\begin{array}{l}\text { healthy controls } \\
\text { stable COPD }\end{array}$ & $\begin{array}{l}15 \\
31\end{array}$ & $\begin{aligned} r(\log \text { leptin-BMI }) & =0.874^{*} \\
r(\log \text { leptin-BMI }) & =0.706^{*}\end{aligned}$ \\
\hline Luo [26], 2005 & $\begin{array}{l}\text { healthy controls } \\
\text { stable COPD }\end{array}$ & $\begin{array}{l}17 \\
29\end{array}$ & $\begin{aligned} r(\log \text { leptin-BMI }) & =0.596^{*} \\
r(\log \text { leptin-BMI }) & =0.409^{*}\end{aligned}$ \\
\hline Calikoglu [16], 2004 & $\begin{array}{l}\text { healthy controls } \\
\text { stable COPD } \\
\text { AECOPD }\end{array}$ & $\begin{array}{l}15 \\
26 \\
16\end{array}$ & $\begin{aligned} \mathrm{r}(\text { leptin-BMI }) & =0.748^{*} \\
\mathrm{r}(\text { leptin-BMI }) & =0.454^{*} \\
\mathrm{r}(\text { leptin-BMI }) & =0.379^{\mathrm{NS}}\end{aligned}$ \\
\hline Yuan [17], 2000 & $\begin{array}{l}\text { COPD with cachexia } \\
\text { COPD without cachexia }\end{array}$ & $\begin{array}{l}12 \\
19\end{array}$ & $\begin{aligned} \mathrm{r}(\text { leptin-BMI }) & =0.643^{*} \\
\mathrm{r}(\text { leptin-BMI }) & =0.965^{*}\end{aligned}$ \\
\hline Yang [35], 2006 & $\begin{array}{l}\text { COPD with cachexia } \\
\text { COPD without cachexia } \\
\text { AECOPD }\end{array}$ & $\begin{array}{l}18 \\
29 \\
25\end{array}$ & $\begin{aligned} \mathrm{r}(\text { leptin-BMI }) & =0.645^{*} \\
\mathrm{r}(\text { leptin-BMI }) & =0.441^{*} \\
\mathrm{r}(\text { leptin-BMI }) & =0.385^{\mathrm{NS}}\end{aligned}$ \\
\hline Shin [18], 2007 & stable COPD & 60 & $\mathrm{r}($ leptin-BMI $)=0.779^{*}$ \\
\hline Krdar [32], 2009 & $\begin{array}{l}\text { stable COPD } \\
\text { AECOPD }\end{array}$ & $\begin{array}{l}15 \\
21\end{array}$ & $\begin{aligned} \mathrm{r}(\text { leptin-BMI }) & =0.689^{*} \\
\mathrm{r}(\text { leptin-BMI }) & =0.563^{*}\end{aligned}$ \\
\hline Eker [19], 2010 & stable COPD & 55 & $\mathrm{r}($ leptin-BMI $)=0.333^{*}$ \\
\hline Bruno [20], 2011 & stable COPD & 27 & $\mathrm{r}($ leptin-BMI $)=0.63^{*}$ \\
\hline Kythreotis [34], 2009 & healthy controls & 25 & $\mathrm{r}\left(\right.$ leptin-FM\%) $=0.780^{*}$ \\
\hline Calikoglu [16], 2004 & $\begin{array}{l}\text { healthy controls } \\
\text { stable COPD } \\
\text { AECOPD }\end{array}$ & $\begin{array}{l}15 \\
26 \\
16\end{array}$ & $\begin{aligned} \mathrm{r}(\text { leptin-FM\% }) & =0.856^{*} \\
\mathrm{r}(\text { leptin-FM\% } & =0.570^{*} \\
\mathrm{r}(\text { leptin-FM\% }) & =0.045^{\mathrm{NS}}\end{aligned}$ \\
\hline Shin [18], 2007 & stable COPD & 60 & $\mathrm{r}(\mathrm{leptin}-\mathrm{FM} \%)=0.806^{*}$ \\
\hline Eker [19], 2010 & stable COPD & 55 & $\mathrm{r}(\mathrm{leptin}-\mathrm{FM} \%)=0.365^{*}$ \\
\hline
\end{tabular}

NS $=$ Nonsignificant. ${ }^{*} \mathrm{p}<0.05$.

$(r=0.45$; fig. 2). Likewise, we found the correlation between circulation leptin levels (log transformed) and BMI in healthy controls $(r=0.77)$ was stronger in comparison with that in stable COPD patients $(\mathrm{r}=0.58$; online suppl. fig. 1; see www.karger.com/doi/10.1159/000354191).

The combined $r$ between the circulating leptin levels and FM\% was 0.62 in stable COPD patients, which predicted a positive correlation in them $(\mathrm{z}=0.72 ; 95 \% \mathrm{CI}$, $0.24-1.20 ; p=0.003 ; I^{2}=86.6 \%$; random effect model). In the healthy controls (two studies), the correlation was stronger $(r=0.811)$ but it was absent in AECOPD patients (1 study; fig. 3 ).

\section{Relationship between Circulating Leptin Levels and}

Gender Differences in Stable COPD Patients

Three studies observed circulating leptin levels after stratification for gender between COPD patients and controls (table 2). Within COPD patients, male subjects had lower levels of circulating leptin compared with female subjects. Cohen et al. [24] had the two groups matched for BMI, and Breyer et al. [25] additionally had the leptin levels corrected for FM\%. The gender-related differences were also observed within healthy controls. There was no difference between the COPD patients and the healthy groups.

\section{Correlation between Circulating Leptin Levels and}

\section{Systemic Inflammatory Biomarkers}

A correlation between circulating leptin and tumor necrosis factor (TNF)- $a$ was reported in 5 of 10 studies, regardless of age, sex, nutritional aspects and the severity of disease. The $\mathrm{z}$ value was -0.02 ( $95 \% \mathrm{CI},-0.35$ to 0.31 ; $\mathrm{p}=0.907 ; \mathrm{I}^{2}=68.5 \%$; random effect model) in stable COPD; the combined $\mathrm{r}$ was -0.02 , indicating that there 


\begin{tabular}{|c|c|c|c|}
\hline \multicolumn{2}{|l|}{ First author, year } & $\mathrm{ES}(95 \% \mathrm{CI})$ & Weight, \% \\
\hline \multicolumn{4}{|l|}{ Healthy controls } \\
\hline Calikoglu [16], 1997 & & $0.97(0.40,1.53)$ & 10.65 \\
\hline Subtotal & & $0.97(0.40,1.53)$ & 10.65 \\
\hline \multicolumn{4}{|l|}{ Stable COPD } \\
\hline Yuan [17], 2000 & $\rightarrow$ & $1.53(1.16,1.90)$ & 13.73 \\
\hline Calikoglu [16], 2004 & $\rightarrow-\frac{1}{1}$ & $0.45(-0.51,1.41)$ & 6.14 \\
\hline Yang [35], 2006 & -1 & $0.59(0.29,0.88)$ & 14.92 \\
\hline Shin [18], 2007 & - & $1.04(0.78,1.30)$ & 15.43 \\
\hline $\operatorname{Krdar}[32], 2009$ & $!$ & $0.85(0.28,1.41)$ & 1.065 \\
\hline Eker [19], 2010 & $\rightarrow$ & $0.35(0.07,0.62)$ & 15.24 \\
\hline Bruno [20], 2011 & $\rightarrow-$ & $0.74(0.34,1.14)$ & 13.25 \\
\hline Subtotal: $\mathrm{I}^{2}=81.0 \%, \mathrm{p}=0.000$ & 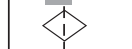 & $0.81(0.49,1.14)$ & 89.35 \\
\hline \multicolumn{4}{|c|}{ Note: weights are from random effect analysis } \\
\hline \multicolumn{4}{|l|}{ AECOPD } \\
\hline Calikoglu [16], 2004 & $-\frac{1}{-1}$ & $0.40(-0.14,0.94)$ & 24.58 \\
\hline Yang [35], 2006 & 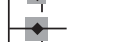 & $0.41(-0.01,0.82)$ & 41.56 \\
\hline Krdar [32], 2009 & $\rightarrow-$ & $0.64(-0.17,1.10)$ & 33.86 \\
\hline Subtotal: $\mathrm{I}^{2}=0.0 \%, \mathrm{p}=0.723$ & 1) & $0.48(0.21,0.75)$ & 100.00 \\
\hline-5 & 0 & 5 & \\
\hline
\end{tabular}

Fig. 2. Correlation coefficient (r) between circulating leptin levels and BMI. $r^{\prime}=0.67$ (using reverse Fisher's $z$ transformation); $\mathrm{z}=$ the value of $\mathrm{r}$ after using Fisher's $\mathrm{z}$ transformation. $\mathrm{ES}=$ Overall effect of $\mathrm{z}$.

\begin{tabular}{|c|c|c|c|}
\hline \multicolumn{2}{|l|}{ First author, year } & ES $(95 \%$ CI) & Weight, \% \\
\hline \multicolumn{4}{|l|}{ Healthy controls } \\
\hline Calikoglu [16], 2004 & - & $1.28(0.71,1.84)$ & 35.20 \\
\hline Kythreotis [34], 2009 & $\rightarrow-$ & $1.04(0.63,1.46)$ & 64.80 \\
\hline Subtotal: $I^{2}=0.0 \%, p=0.516$ & (1) & $1.13(0.79,1.46)$ & 100.00 \\
\hline \multicolumn{4}{|l|}{ Stable COPD } \\
\hline Calikoglu [16], 2004 & $\multimap-$ & $0.65(0.24,1.06)$ & 24.23 \\
\hline Shin [18], 2007 & $\rightarrow$ & $1.12(0.86,1.37)$ & 27.47 \\
\hline Eker [19], 2010 & $\rightarrow-1$ & $0.38(0.11,0.66)$ & 27.21 \\
\hline Subtotal: $I^{2}=86.6 \%, p=0.001$ & & $0.72(0.24,1.20)$ & 78.90 \\
\hline \multicolumn{4}{|l|}{ AECOPD } \\
\hline Calikoglu [16], 2004 & & $0.05(-0.50,0.59)$ & 21.10 \\
\hline Subtotal & & $0.05(-0.50,0.59)$ & 21.10 \\
\hline \multicolumn{4}{|c|}{ Note: weights are from random effect analysis } \\
\hline-5 & & 5 & \\
\hline
\end{tabular}

Fig. 3. Correlation coefficient $(r)$ between circulating leptin levels and $F M \% . r^{\prime}=0.81$ (using reverse Fisher's z transformation) in healthy controls; $\mathrm{z}=$ the value of $\mathrm{r}$ after using Fisher's $\mathrm{z}$ transformation. $\mathrm{r}^{\prime}=0.62$ (using reverse Fisher's $\mathrm{z}$ transformation) in stable COPD. ES = Overall effect of $\mathrm{z}$. 
Table 2. Circulating leptin levels between stable COPD patients and healthy controls by gender (means \pm SD)

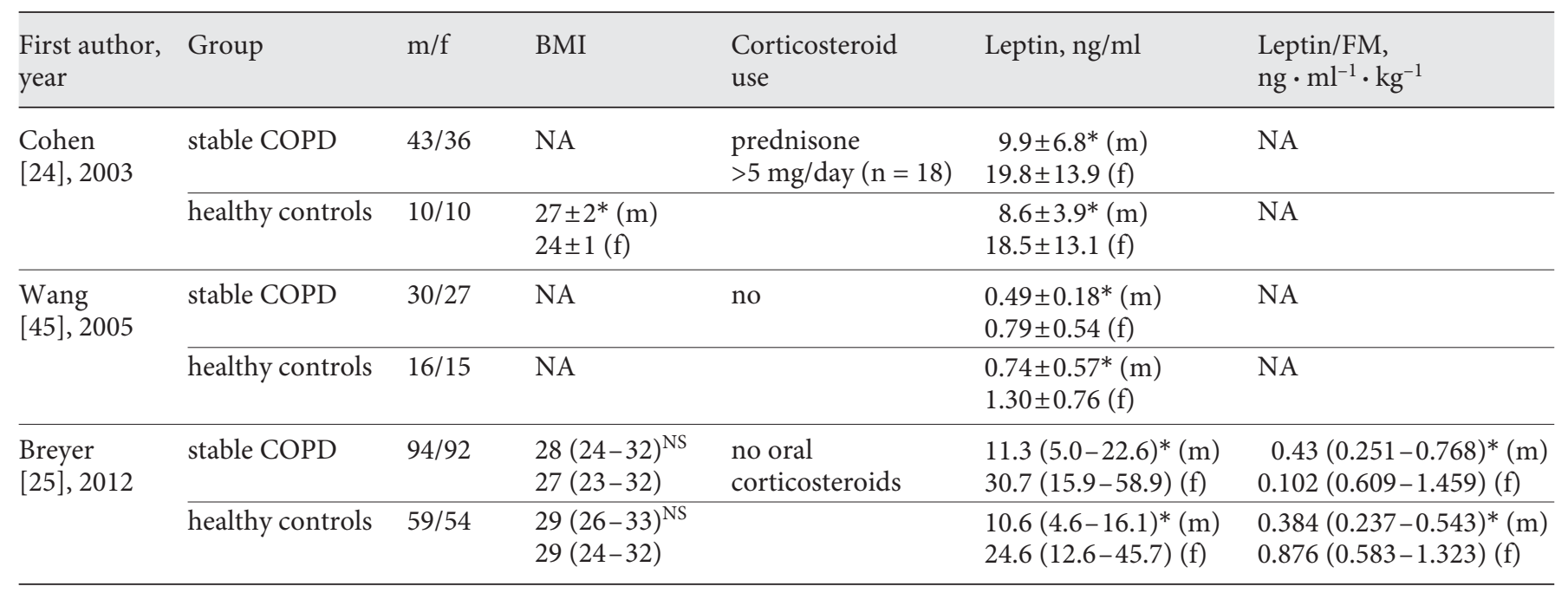

$\mathrm{NA}=$ Not available; $\mathrm{NS}=$ nonsignificant vs. female counterparts. ${ }^{*} \mathrm{p}<0.05$ vs. female counterparts.

The values of Breyer et al. [25] are medians (25-75 percentiles).

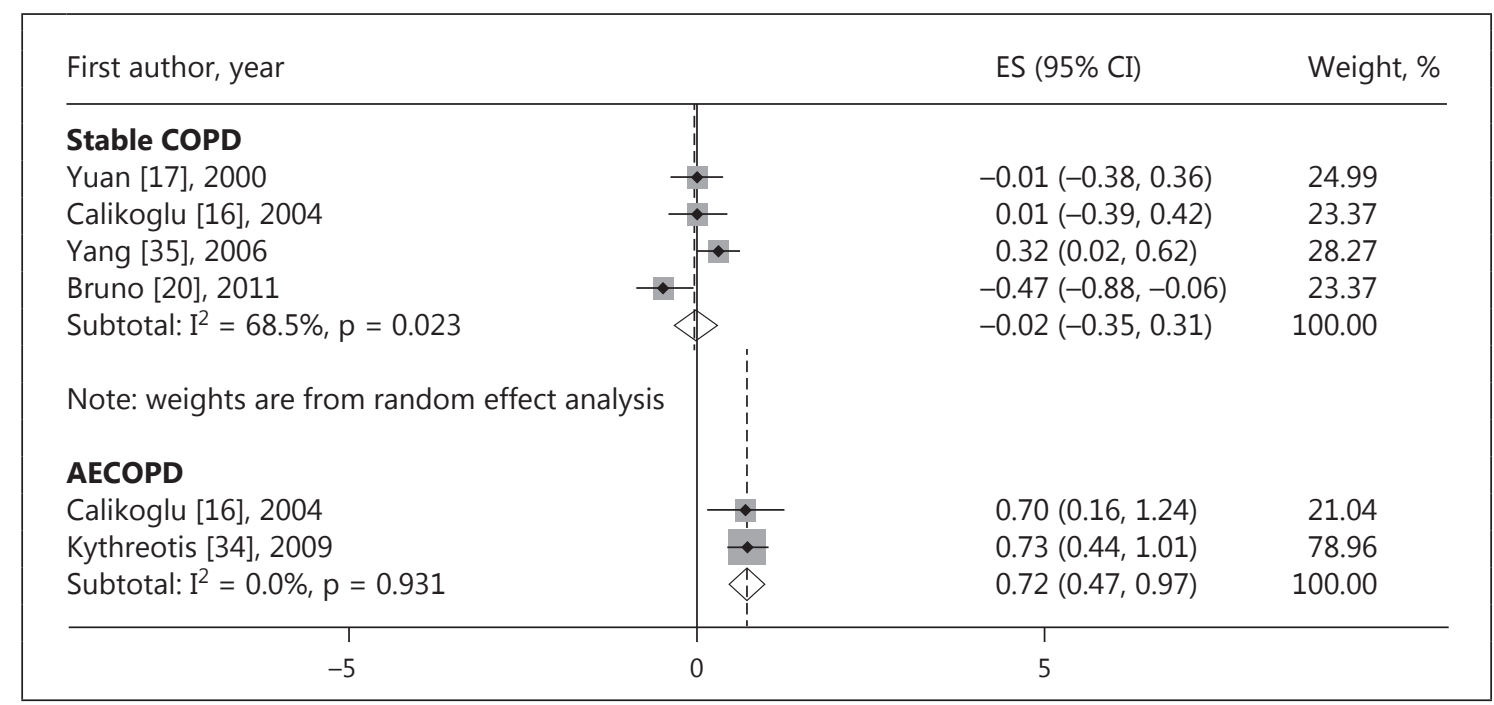

Fig. 4. Correlation coefficient ( $r$ ) between circulating leptin levels and TNF- $\alpha . r^{\prime}=-0.02$ (using reverse Fisher's z transformation) in stable COPD; $z=$ the value of $r$ after using Fisher's $z$ transformation. $r^{\prime}=0.62$ (using reverse Fisher's z transformation) in AECOPD. ES = Overall effect of $\mathrm{z}$.

was no significant correlation between the circulating leptin and TNF- $\alpha$ levels in the stable COPD. On the contrary, a positive correlation $(\mathrm{r}=0.617)$ was shown in AECOPD in 2 studies (fig. 4).

Breyer et al. [25] reported that circulating leptin correlated with $\mathrm{C}$-reactive protein $(\mathrm{CRP})$ and fibrinogen, but

Circulating Leptin in COPD Patients not with interleukin (IL)-6 in 186 patients with stable COPD. However, no such correlation was found in another study [26]. Krommidas et al. [27] indicated that the log-transformed leptin blood concentration was significantly positively associated with CRP and IL-6 in AECOPD (table 3). 
Table 3. Correlation between circulating leptin levels and systemic inflammatory biomarkers

\begin{tabular}{|c|c|c|c|}
\hline First author, year & Group & $\mathrm{n}$ & r value or main message \\
\hline Takabatake [29], 1999 & healthy controls & 15 & leptin-sTNF-R/TNF- $a^{N S}$ \\
\hline Luo [26], 2005 & healthy controls & 17 & leptin-TNF-a ${ }^{\mathrm{NS}}$ \\
\hline Takabatake [29], 1999 & stable COPD & 31 & leptin-sTNF-R/TNF-a ${ }^{N S}$ \\
\hline Yuan [17], 2000 & COPD with cachexia & 12 & $\mathrm{r}(\mathrm{leptin}-\mathrm{TNF}-\alpha)=-0.343^{\mathrm{NS}}$ \\
\hline Cohen [24], 2003 & stable COPD & 79 & $\mathrm{r}\left(\right.$ leptin-sTNF-R55) $=0.1, \mathrm{NS} ; \mathrm{r}\left(\right.$ leptin-sTNF-R75) $=0.07^{\mathrm{NS}}$ \\
\hline Calikoglu [16], 2004 & stable COPD & 26 & $\mathrm{r}($ leptin-TNF- $\alpha)=0.014^{\mathrm{NS}}$ \\
\hline Luo [26], 2005 & stable COPD & 29 & leptin-TNF-a ${ }^{\mathrm{NS}}$ \\
\hline \multirow[t]{2}{*}{ Yang [35], 2006} & COPD with cachexia & 18 & $\mathrm{r}($ leptin-TNF- $\alpha)=0.344^{\mathrm{NS}}$ \\
\hline & COPD without cachexia & 29 & $\mathrm{r}($ leptin-TNF- $\alpha)=0.287^{\mathrm{NS}}$ \\
\hline Kythreotis [34], 2009 & AECOPD & 52 & $\mathrm{r}($ leptin-TNF- $\alpha)=0.620^{*}$ \\
\hline Krommidas [27], 2010 & AECOPD & 63 & $\log$ leptin-TNF- $a^{\text {NS }}$ \\
\hline Luo [26], 2005 & stable COPD & 29 & leptin-CRP ${ }^{N S}$ \\
\hline Krommidas [27], 2010 & AECOPD & 63 & log leptin-CRP (significant positive correlation) \\
\hline Breyer [25], 2012 & stable COPD & 186 & $\mathrm{r}($ leptin-CRP $)=0.34^{*}$ \\
\hline Krommidas [27], 2010 & AECOPD & 63 & log leptin-IL-6 (significant positive correlation) \\
\hline Breyer [25], 2012 & stable COPD & 186 & $\mathrm{r}\left(\right.$ leptin-IL-6) $=0.01^{\mathrm{NS}}$ \\
\hline Breyer [25], 2012 & stable COPD & 186 & $\mathrm{r}($ leptin-fibrinogen $)=0.20^{*}$ \\
\hline
\end{tabular}

NS $=$ Nonsignificant. ${ }^{*} \mathrm{p}<0.05$.

\section{Circulating Leptin Levels in Stable COPD and} AECOPD Patients

COPD patients were divided into two groups: (1) AECOPD, which was defined as a change in the patient's baseline dyspnea, cough and/or sputum that is beyond normal day-to-day variations and might warrant a change in regular medication [28], and (2) stable COPD, where the patients were clinically stable for at least 4 weeks without clinical evidence of exacerbation. All studies listed in table 4 provided basic information related to patients and control subjects.

Three studies $[18,26,29]$ reported that patients with stable COPD had lower leptin levels concomitant with a significantly lower BMI than healthy controls. After correction for FM\%, no difference was noted between patients and controls $[18,25,30]$. Eker et al. [19] found that in stable COPD patients leptin levels were low and the frequency of insulin resistance was high compared with the controls, although no difference in body FM was determined between the study populations. In other studies where COPD patients and controls were well matched for age, gender and BMI, the circulating leptin levels were not significantly different between stable COPD patients and healthy controls [17, 24, 25, 30-32]. However, Gaki et al. [33] demonstrated that leptin levels were higher in COPD patients who used inhaled corticosteroids.

Although AECOPD patients had significantly lower BMI than control subjects, Kythreotis et al. [34] demonstrated that leptin levels in these patients were significantly higher than those in healthy subjects even after correction for FM\%. After matching for BMI between the exacerbation group and healthy controls, elevated leptin levels were observed [16, 32, 35], though they were not significantly different in the study of Yang et al. [35]. The leptin levels were not different between the exacerbation and stable COPD groups [32, 35], while Calikoglu et al. [16] reported that leptin levels were higher in AECOPD patients than in patients with stable COPD. 
Table 4. Circulating leptin levels between stable COPD/AECOPD patients and healthy controls

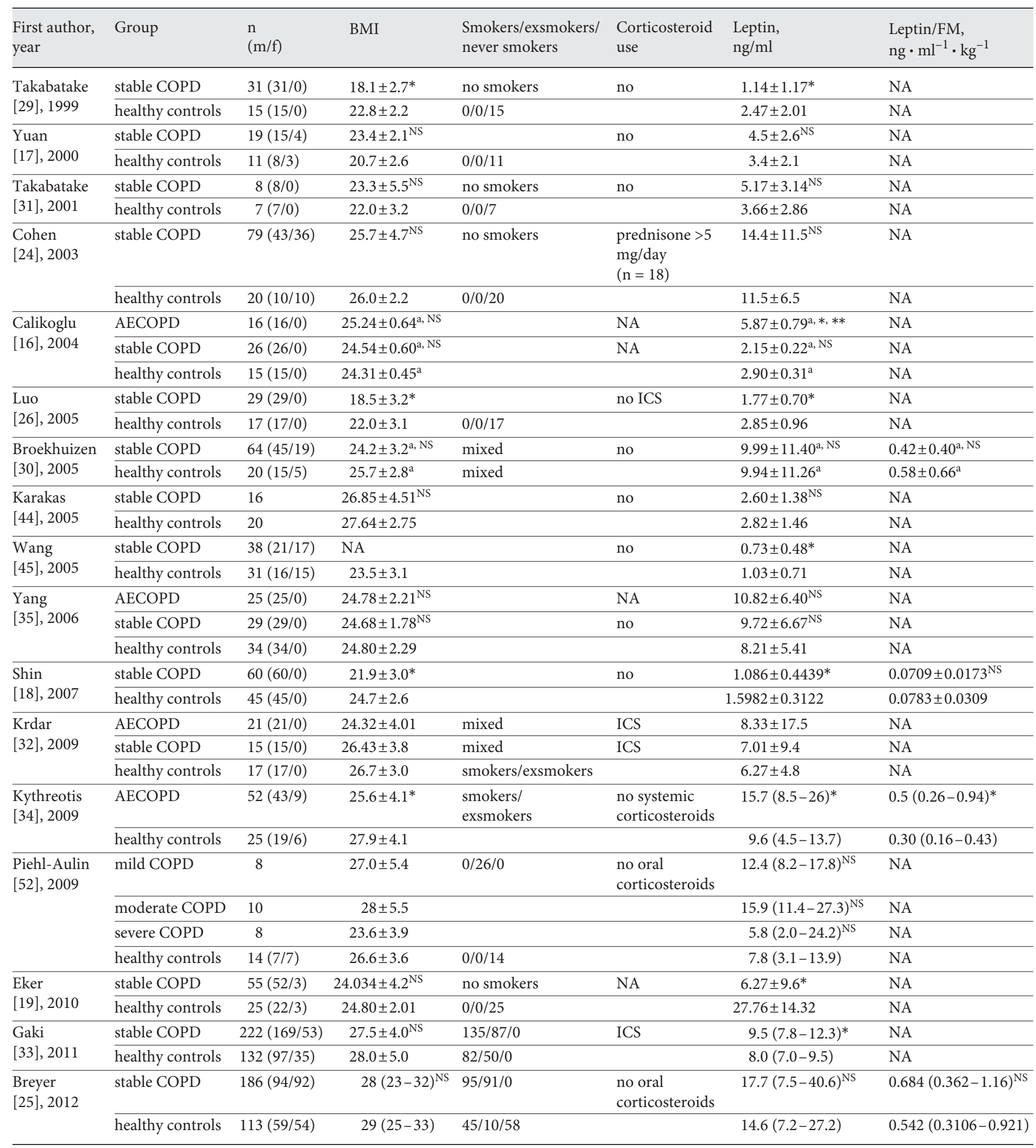

ICS = Inhaled corticosteroids; NA = not available; NS = nonsignificant (circulating leptin levels between stable COPD/AECOPD and healthy controls). ${ }^{*} \mathrm{p}<0.05$ (circulating leptin levels between stable group/AECOPD group and healthy controls); ${ }^{* *} \mathrm{p}<0.05$ (circulating leptin levels between AECOPD and stable COPD). Values are numbers, means $\pm \mathrm{SD}$ ( or $^{\mathrm{a}}$ means $\pm \mathrm{SE}$ ) or medians $(25-75$ percentiles). 


\section{Discussion}

Our study showed that BMI, FM\% and gender were the dominant determinants of circulating leptin levels in stable COPD patients, whilst the correlation between $\mathrm{BMI}$ and leptin levels tended to be weaker during acute exacerbation compared with the stable status. In addition, a positive correlation between leptin levels and inflammatory markers was observed in AECOPD patients and this correlation did not seem to be statistically significant in patients with stable COPD.

Leptin is a protein hormone (mainly synthesized in adipocytes) that plays an important role in body weight regulation [36] through the afferent hormonal signal to the brain in a feedback mechanism that regulates FM [37, 38]. In addition, leptin mediates energy expenditure by increasing both physical activity and activity-independent thermogenesis [39].

It was reported that circulating leptin levels varied with the nutritional status in the general population [4043]. Likewise, in our meta-analysis, circulating leptin levels were correlated with nutritional parameters in COPD patients. Four articles $[17,30,35,44]$ reported that circulating leptin levels decreased in COPD patients with lower BMI compared to healthy controls, which was not consistent with the small study of Takabatake et al. [31], who reported that no difference was found between stable COPD patients and healthy controls. In addition, there was no difference in either circulating leptin levels or BMI between noncachexic COPD patients and healthy controls. Wang et al. [45] also reported similar results for leptin although they did not provide information regarding BMI.

Given the same amount of FM in normal subjects, women had higher circulating leptin levels than men [46]. This gender difference was also observed in circulating leptin levels in COPD patients [25]. However, there seemed to be no significant difference between COPD patients and healthy controls with respect to the magnitude of gender-related differences in body composition. Several other adipokines were found in humans $[19,27,34]$, and analysis of their expression together with leptin levels may explain the possible mechanism of weight loss in COPD patients.

Recent studies $[16,17,35]$ suggest that cytokine-mediated metabolic derangement is among the candidates responsible for weight loss in COPD patients. Experimental animal [21, 47] and human [48] studies have provided evidence for a link between leptin and proinflammatory cytokines. Our meta-analysis was unable to show any sta- tistically significant correlation between circulating leptin and TNF- $\alpha$ levels in stable COPD patients, suggesting that leptin might not be primarily under the control of the TNF- $\alpha$ system. Improved TNF- $\alpha$ test specificity over years could be a likely explanation for the discrepancy between recent and earlier reports [49]. Breyer et al. [25] reported that leptin correlated with CRP and fibrinogen, but not with IL-6 in stable COPD patients, which was inconsistent with the study of Luo et al. [26]. Interestingly, a similar relationship between leptin and CRP/fibrinogen persisted in female COPD patients but disappeared in male counterparts [25]. This linkage might be involved in the association of adipose tissue with oxidative stress and enhanced oxidative capacity of circulating leptin by leukocytes [50]. The controversial results indicate a need for longitudinal studies to confirm the correlation between circulating leptin levels and systemic inflammation in COPD patients.

Development of progressive weight loss in COPD patients was reported to be independent of the degree of airway limitation [51]. In line with this, another study [52] also reported that there was no correlation between circulating leptin levels and the severity of disease. Eker et al. [19] indicated a positive relationship between leptin levels and $\mathrm{FEV}_{1} /$ forced vital capacity. Although there was a prominent difference in leptin levels between moderate, severe and very severe COPD groups, it was not statistically significant [19]. The inconsistent conclusions might be related to the small number of patients.

Circulating leptin levels in stable COPD patients did not seem to be different from those in healthy controls after age, gender and BMI were adjusted. Additionally, the leptin levels tended to be higher in AECOPD patients as compared with the healthy controls. As an appropriate treatment, glucocorticosteroids might be used in COPD patients. The higher leptin levels in COPD patients demonstrated by Gaki et al. [33] and Creutzberg et al. [53] were probably influenced by corticosteroids [54]. However, whether the administration of corticosteroids could affect serum leptin levels was still controversial [27, 55, 56] and is worthy of further exploration. Eker et al. [19] reported a significantly lower circulating leptin level in stable COPD patients than other studies, which might be attributable to the lower fat-free mass and higher frequency of insulin resistance in COPD patients. It was therefore important to minimize selection biases on any influencing factors in future studies between the study and control populations.

During disease exacerbation, the correlation between circulating leptin levels and nutritional parameters tend- 
ed to be weaker compared to that in stable COPD patients. Temporary disturbances in energy balance during an AECOPD might be related to increased leptin concentrations and systemic inflammatory responses [27, 53]. It was shown that the administration of cytokines such as TNF- $\alpha$ could increase serum leptin levels [48]. Moreover, Creutzberg et al. [6] demonstrated a positive correlation between leptin and soluble TNF- $\alpha$ receptors during COPD exacerbations. The present review seemed to suggest that there was a positive relationship between circulating leptin and TNF- $\alpha$ levels and that systemic inflammation might be conducive to a dissociation of the normal feedback regulation of leptin by nutritional parameters.

There are some limitations concerning the literature search used for our meta-analysis. First, the control subjects are not matched for BMI, FM\% and the smoking status, which could influence circulating leptin levels. Therefore, we could not do statistical analyses to evaluate the leptin levels between COPD patients and controls. It is important to minimize selection biases in future studies and ensure that there is no significant difference in nutritional parameters between the study and control populations. Second, we were not able to account for the number of current smokers, former smokers or the number of pack-years, as they were insufficiently presented in most studies. Finally, we could not show whether airway leptin concentrations had a closer correlation with clinical parameters in COPD patients than circulating leptin levels due to the lack of available data.
In conclusion, our study suggests that gender-related circulating leptin remains regulated physiologically in stable COPD and varies with the nutritional status, which seems to be independent of the TNF- $\alpha$ system, probably as a compensatory mechanism to preserve body fat content. However, it is tempting to speculate that an inappropriate increase in leptin levels during an AECOPD and the additional correlation with systemic inflammatory responses may be related with changes in nutritional parameters, suggesting that leptin is valuable in the evaluation of systemic inflammatory responses in AECOPD patients. Large-scale studies are needed to better identify the role of leptin.

\section{Acknowledgments}

This study was supported by the National Major Scientific and Technological Special Project for 'Significant New Drugs Development' (2011ZX09302-003-02), Jiangsu Province Major Scientific and Technological Special Project (BM2011017) and the Priority Academic Program Development of Jiangsu Higher Education Institutions (PAPD, JX10231801).

\section{Financial Disclosure and Conflicts of Interest}

The authors declare that they have no competing interests.

\section{References}

1 GOLD: Global Strategy for Diagnosis, Management, and Prevention of COPD (Revised 2011). http://www.goldcopd.org/guidelinesglobal-strategy-for-diagnosis-management. html.

-2 Murray CJ, Lopez AD: Evidence-based health policy - lessons from the Global Burden of Disease Study. Science 1996;274:740-743.

3 Raherison C, Girodet PO: Epidemiology of COPD. Eur Respir Rev 2009;18:213-221.

4 Gray-Donald K, Gibbons L, Shapiro SH, Macklem PT, Martin JG: Nutritional status and mortality in chronic obstructive pulmonary disease. Am J Respir Crit Care Med 1996; 153:961-966.

5 Schols AM, Slangen J, Volovics L, Wouters EF: Weight loss is a reversible factor in the prognosis of chronic obstructive pulmonary disease. Am J Respir Crit Care Med 1998; 157(6 Pt 1):1791-1797.
-6 Creutzberg EC, Wouters EF, Mostert R, Weling-Scheepers CA, Schols AM: Efficacy of nutritional supplementation therapy in depleted patients with chronic obstructive pulmonary disease. Nutrition 2003;19:120-127.

7 Yoneda T, Yoshikawa M, Fu A, Tsukaguchi K, Okamoto Y, Takenaka H: Plasma levels of amino acids and hypermetabolism in patients with chronic obstructive pulmonary disease. Nutrition 2001;17:95-99.

-8 Sridhar MK, Carter R, Lean ME, Banham SW: Resting energy expenditure and nutritional state of patients with increased oxygen cost of breathing due to emphysema, scoliosis and thoracoplasty. Thorax 1994;49:781-785.

-9 Auwerx J, Staels B: Leptin. Lancet 1998;351: 737-742.

10 Flier JS: Leptin expression and action: new experimental paradigms. Proc Natl Acad Sci USA 1997;94:4242-4245.
11 Faggioni R, Feingold KR, Grunfeld C: Leptin regulation of the immune response and the immunodeficiency of malnutrition. FASEB J 2001;15:2565-2571.

12 Schols AM, Soeters PB, Mostert R, Saris WH, Wouters EF: Energy balance in chronic obstructive pulmonary disease. Am Rev Respir Dis 1991;143:1248-1252.

13 Barnes PJ: The cytokine network in asthma and chronic obstructive pulmonary disease. J Clin Invest 2008;118:3546-3556.

14 Schols AM, Creutzberg EC, Buurman WA, Campfield LA, Saris WH, Wouters EF: Plasma leptin is related to proinflammatory status and dietary intake in patients with chronic obstructive pulmonary disease. Am J Respir Crit Care Med 1999;160:1220-1226.

15 Bruno A, Chanez P, Chiappara G, et al: Does leptin play a cytokine-like role within the airways of COPD patients? Eur Respir J 2005;26: 398-405. 
16 Calikoglu M, Sahin G, Unlu A, et al: Leptin and TNF-alpha levels in patients with chronic obstructive pulmonary disease and their relationship to nutritional parameters. Respiration 2004;71:45-50.

-17 Yuan Y, Wang Z, Liu C: Preliminary investigation of effect of serum leptin on nutritional state of COPD patients (in Chinese). Zhonghua Jie He He Hu Xi Za Zhi 2000;23:292-295.

-18 Shin KC, Chung JH, Lee KH: Effects of TNFalpha and leptin on weight loss in patients with stable chronic obstructive pulmonary disease. Korean J Intern Med 2007;22:249255.

19 Eker S, Ayaz L, Tamer L, Ulubas B: Leptin, visfatin, insulin resistance, and body composition change in chronic obstructive pulmonary disease. Scand J Clin Lab Invest 2010;70: 40-44.

20 Bruno A, Alessi M, Soresi S, et al: Increased leptin/leptin receptor pathway affects systemic and airway inflammation in COPD former smokers. J Inflamm Res 2011;4:51-59.

-21 Grunfeld C, Zhao C, Fuller J, et al: Endotoxin and cytokines induce expression of leptin, the ob gene product, in hamsters. J Clin Invest 1996;97:2152-2157.

22 Herrejon A, Palop J, Inchaurraga I, et al: Low doses of megestrol acetate increase weight and improve nutrition status in patients with severe chronic obstructive pulmonary disease and weight loss (in Spanish). Med Clin (Barc) 2011;137:193-198.

23 Fisher RA, Genetiker S, Fisher RA, et al: Statistical Methods for Research Workers. Edinburgh, Oliver \& Boyd, 1970, vol 14.

24 Cohen RI, Marzouk K, Berkoski P, O’Donnell CP, Polotsky VY, Scharf SM: Body composition and resting energy expenditure in clinically stable, non-weight-losing patients with severe emphysema. Chest 2003;124:13651372.

25 Breyer MK, Rutten EP, Locantore NW, Watkins ML, Miller BE, Wouters EF: Dysregulated adipokine metabolism in chronic obstructive pulmonary disease. Eur J Clin Invest 2012;42:983-991.

\26 Luo FM, Liu XJ, Li SQ, Wang ZL, Liu CT, Yuan YM: Circulating ghrelin in patients with chronic obstructive pulmonary disease. $\mathrm{Nu}$ trition 2005;21:793-798.

-27 Krommidas G, Kostikas K, Papatheodorou G, et al: Plasma leptin and adiponectin in COPD exacerbations: associations with inflammatory biomarkers. Respir Med 2010;104:40-46.

28 Rodriguez-Roisin R: Toward a consensus definition for COPD exacerbations. Chest 2000; 117(5 suppl 2):398S-401S.

29 Takabatake N, Nakamura H, Abe S, et al: Circulating leptin in patients with chronic obstructive pulmonary disease. Am J Respir Crit Care Med 1999;159(4 Pt 1):1215-1219.
30 Broekhuizen R, Grimble RF, Howell WM, et al: Pulmonary cachexia, systemic inflammatory profile, and the interleukin lbeta -511 single nucleotide polymorphism. Am J Clin Nutr 2005;82:1059-1064.

-31 Takabatake N, Nakamura H, Minamihaba O, et al: A novel pathophysiologic phenomenon in cachexic patients with chronic obstructive pulmonary disease: the relationship between the circadian rhythm of circulating leptin and the very low-frequency component of heart rate variability. Am J Respir Crit Care Med 2001;163:1314-1319.

- 32 Krdar S, Serter M, Ceylan E, Sener AG, Kavak T, Karadag F: Adiponectin as a biomarker of systemic inflammatory response in smoker patients with stable and exacerbation phases of chronic obstructive pulmonary disease. Scand J Clin Lab Invest 2009;69:219-224.

33 Gaki E, Kontogianni K, Papaioannou AI, et al: Associations between BODE index and systemic inflammatory biomarkers in COPD. COPD 2011;8:408-413.

34 Kythreotis P, Kokkini A, Avgeropoulou S, et al: Plasma leptin and insulin-like growth factor I levels during acute exacerbations of chronic obstructive pulmonary disease. BMC Pulm Med 2009;9:11.

35 Yang YM, Sun TY, Liu XM: The role of serum leptin and tumor necrosis factor-alpha in malnutrition of male chronic obstructive pulmonary disease patients. Chin Med J (Engl) 2006;119:628-633.

36 Considine RV: Human leptin: an adipocyte hormone with weight-regulatory and endocrine functions. Semin Vasc Med 2005;5:1524.

- 37 Tartaglia LA: The leptin receptor. J Biol Chem 1997;272:6093-6096.

38 Kokturk O, Bukan N, Bilgihan A: Leptin and ghrelin levels in patients with obstructive sleep apnea syndrome. Respiration 2005;72: 395-401.

39 Collins S, Kuhn CM, Petro AE, Swick AG, Chrunyk BA, Surwit RS: Role of leptin in fat regulation. Nature 1996;380:677.

40 Considine RV, Sinha MK, Heiman ML, et al: Serum immunoreactive-leptin concentrations in normal-weight and obese humans. N Engl J Med 1996;334:292-295.

41 Hamilton BS, Paglia D, Kwan AY, Deitel M: Increased obese mRNA expression in omental fat cells from massively obese humans. Nat Med 1995;1:953-956.

42 Maffei M, Halaas J, Ravussin E, et al: Leptin levels in human and rodent: measurement of plasma leptin and ob RNA in obese and weight-reduced subjects. Nat Med 1995;1: 1155-1161.

43 Tasaka S, Hasegawa N, Nishimura T, et al: Elevated serum adiponectin level in patients with Mycobacterium avium-intracellulare complex pulmonary disease. Respiration 2009;79:383-387.
44 Karakas S, Karadag F, Karul AB, et al: Circulating leptin and body composition in chronic obstructive pulmonary disease. Int J Clin Pract 2005;59:1167-1170.

45 Wang QY, Zhang H, Yan X, Kang J, Yu RJ: Serum resistin and leptin in patients with chronic obstructive pulmonary disease and their relationship to nutritional state (in Chinese). Zhonghua Jie $\mathrm{He} \mathrm{He} \mathrm{Hu} \mathrm{Xi} \mathrm{Za} \mathrm{Zhi}$ 2005;28:445-447.

46 Abdullah SM, Khera A, Leonard D, et al: Sex differences in the association between leptin and CRP: results from the Dallas Heart Study. Atherosclerosis 2007;195:404-410.

47 Sarraf P, Frederich RC, Turner EM, et al: Multiple cytokines and acute inflammation raise mouse leptin levels: potential role in inflammatory anorexia. J Exp Med 1997;185:171175

48 Zumbach MS, Boehme MW, Wahl P, Stremmel W, Ziegler R, Nawroth PP: Tumor necrosis factor increases serum leptin levels in humans. J Clin Endocrinol Metab 1997;82: 4080-4082.

49 Wagner PD: Possible mechanisms underlying the development of cachexia in COPD. Eur Respir J 2008;31:492-501.

50 Caldefie-Chezet F, Poulin A, Tridon A, Sion B, Vasson MP: Leptin: a potential regulator of polymorphonuclear neutrophil bactericidal action? J Leukoc Biol 2001;69:414-418.

-51 Prescott E, Almdal T, Mikkelsen KL, Tofteng CL, Vestbo J, Lange P: Prognostic value of weight change in chronic obstructive pulmonary disease: results from the Copenhagen City Heart Study. Eur Respir J 2002;20:539_ 544

52 Piehl-Aulin K, Jones I, Lindvall B, Magnuson A, Abdel-Halim SM: Increased serum inflammatory markers in the absence of clinical and skeletal muscle inflammation in patients with chronic obstructive pulmonary disease. Respiration 2009;78:191-196.

53 Creutzberg EC, Wouters EFM, Vanderhoven-Augustin IML, Dentener MA, Schols AMWJ: Disturbances in leptin metabolism are related to energy imbalance during acute exacerbations of chronic obstructive pulmonary disease. Am J Respir Crit Care Med 2000; 162(4 Pt 1):1239-1245

54 Sin DD, Lacy P, York E, Man SF: Effects of fluticasone on systemic markers of inflammation in chronic obstructive pulmonary disease. Am J Respir Crit Care Med 2004;170: 760-765.

55 Tataranni PA, Pratley R, Maffei M, Ravussin E: Acute and prolonged administration of glucocorticoids (methylprednisolone) does not affect plasma leptin concentration in humans. Int J Obes Relat Metab Disord 1997;21: 327-330.

56 Saladin R, Staels B, Auwerx J, Briggs M: Regulation of ob gene expression in rodents and humans. Horm Metab Res 1996;28:638-641. 